\title{
Anábasis de Efraín Barquero: Aproximación a un exotismo en el tiempo
}

\section{Anabasis of Efraín Barquero: Approaching exoticism in time}

\author{
Julio Alberto Rodajo Ureta ${ }^{1}$
}

Como citar este artículo: Rodajo Ureta, J.A. (2021). Anábasis de Efraín Barquero: Aproximación a un exotismo en el tiempo, Pangeas. Revista Interdisciplinar de Ecocrítica (núm. 3) 37-47. https://doi.org/10.14198/ PANGEAS.18874

\begin{abstract}
Resumen
El presente trabajo da cuenta de la forma en que Efraín Barquero (1931-2020), en su poemario El viento de Ios reinos (Editorial Nascimento, 1967/Ediciones Lastarria, 2019), poetiza una China imaginaria, donde resulta fundamental la articulación de un hablante extranjero habitando lo desconocido. El mencionado libro es contacto concreto, producto del viaje que realiza en 1962 a China, lo cual le posibilita componer una reescritura del mundo y de sus obsesiones poéticas, sublimando el entorno en pos de un diálogo con los elementos primordiales y en busca del origen universal de lo humano. A partir de esta develación, se postula que el poemario compone su propio acercamiento a lo remoto, no para intentar formar parte de ello, sino para encontrarse a sí mismo en la "experiencia exótica" teorizada por Victor Segalen; por lo tanto, suspender, por momentos, la diferencia entre hablante y entorno, sugiere el acto estético como una reelaboración de los temas y pulsiones esenciales de su poética, ahora arraigados en una cultura distante e impenetrable.
\end{abstract}

Palabras clave: Efraín Barquero; Exotismo; Orientalismo; Poesía de viaje; China.

\section{Abstract}

This work gives an account of the way in which Efraín Barquero (1931-2020), in his poetry book El viento de los reinos (Editorial Nascimento, 1967 / Ediciones Lastarria, 2019), poetizes an imaginary China, where the articulation of a foreign speaker inhabiting the unknown. The aforementioned book is concrete contact, a product of the trip he made in 1962 to China, which enables him to compose a rewriting of the world and its poetic obsessions, sublimating the environment in pursuit of a dialogue with the primordial elements and in search of universal origin of the human. From this unveiling, it is postulated that the collection of poems composes its own approach to the remote, not to try to be part of it, but to find itself in the "exotic experience" theorized by Victor Segalen; therefore, suspending, at times, the difference between speaker and environment, suggests the aesthetic act as a reworking of the essential themes and drives of his poetics, now rooted in a distant and impenetrable culture.

Key words: Efraín Barquero; Exoticism; Orientalism; Travel Poetry; China.

1. Julio Alberto Rodajo Ureta. Universidad Alberto Hurtado (Santiago de Chile). julioaerre@gmail.com https://orcid.org/0000-0002-3348-9768 (Santiago de Chile, 1994). Licenciado en Lengua y Literatura por la Universidad Alberto Hurtado. Postulante a Magíster en Estudios de la Imagen por la misma institución. 


\section{“¿Quién no ha soñado con Jiang-an? ¿Qué viajero no quiere quedarse para siempre?”}

(Wei Zhuang)

Cabe mencionar que esta publicación consta del primer capítulo de la tesis del autor para optar al grado de licenciado en literatura, la cual se tituló: "Viaje onírico como búsqueda de una identidad universal en El viento de los reinos de Efraín Barquero". Dicha tesis fue desarrollada dentro del Proyecto de Investigación Fondecyt regular 1150699 ("La imaginación del ideograma: entre Pound y Michaux"), cuyo investigador responsable y profesor guía fue Fernando Pérez Villalón. Este artículo fue presentado en el Congreso Internacional de Literatura y Ecocrítica, Segovia 2018, gracias al financiamiento de la Beca Plan Mejoramiento Institucional(PMI UAH1501, 2016-2018) destinada a la participación de estudiantes en congresos y pasantías nacional e internacionales.

\section{INTRODUCCIÓN}

En el año 1967 se publica El viento de los reinos ${ }^{1}$, poemario a partir del cual se define un nuevo vuelco en la poética de Efraín Barquero. Fue iniciado en $1962^{2}$, producto de un viaje que pone rumbo al poeta hacia China, el cual permaneció viviendo allí un par de años, impartiendo clases de español haciendo leer a Manuel Rojas y admirando la supervivencia milenaria de una cultura ajena. Allí, quien ya a los 23 años había publicado su primer libro, La piedra del pueblo (1954), con prólogo de Pablo Neruda, ahonda más complejamente sus temas e inquietudes. En principio, articulándose desde un contexto de cambios y ligándose a un mundo ancestral campesino, la voz poética de Barquero es elaborada en relación con la cotidianidad, con la huella del ser humano, siempre en vínculo con los elementos más primordiales de la existencia misma (el pan, la piedra, el pueblo, el agua, la tierra, la semilla). La nueva propuesta en la producción de Barquero significa un ejercicio que sitúa lo universal en la cultura china, autointerpelándose desde la visión de forastero para, quizá, redescubrirse. El hablante no sólo se propone revelar un misterio del origen, sino que se aventura a construir, a partir del imaginario, una cultura milenaria, que trae al presente a través de la escritura: explora sitios tan remotos como ignotos. Con poemas contenedores de hermetismo, se desplaza el pasado, el presente y el futuro; se enaltece el viento y el fuego; se apropia del asombro y la contemplación, aludiendo a lo transitorio y a lo eterno. De esta manera, su poética se establece desde una dialéctica entre el encuentro y el desencuentro esencial del ser humano con su habitar-en-el-mundo, pensando en un cosmos elemental donde dialoga el fuego del hogar, el vientre de la madre-amada, la presencia del ancestro-padre y la naturaleza adyacente que envuelve al hablante en tanto coincide en una búsqueda de sí mismo.

Respecto al poemario aquí estudiado, años más tarde de su publicación, Floridor Pérez se pronunciaría en una reseña al respecto, señalando que "El viento de los reinos no resulta así un fácil Canto a China [como quizá lo resolvió Pablo de Rokha en su Canto de fuego a China popular] ${ }^{3}$, sino un logrado poema desde su complicado y eterno espíritu. Barquero ha logrado lo que pedía Huidobro: no cantar la rosa: hacerlas florecer en el poema" (Pérez, 1969: 1).

1. Cabe mencionar que el título que escoge Efraín Barquero es una referencia exacta a uno de los libros canónicos del pensamiento chino-budista: se trata del Shijing, conocido como Libro de poemas modelo, donde una serie de cantos están agrupados bajo el título: "Cantos de los reinos". Es importante resaltar este hecho, ya que constata un vínculo con la cultura china desde su título.

2. Según Barquero, la escritura fundamental del poemario fue fuera de China, podría decirse que, en el retorno; sin embargo, no cabe duda de que la obra es producto de un profundo acercamiento a los elementos que componen el imaginario chino clásico. Por otro lado, me gustaría mencionar que he encontrado una versión previa a la primera edición, una suerte de boceto, que data del mismo año en que viaja a China. Bajo el título “Las puertas de China", el autor constata que "Estos transitorios fragmentos han sido compaginados especialmente para ORFEO y pertenecen a un vasto poema aún incompleto". Es importante, para mí, destacar el carácter fragmentario y, a la vez, de largo aliento. Puede encontrarse en Revisa Orfeo N²1-22 (Santiago de Chile, 1996).

3. Lo escrito entre corchetes es agregado por el autor de este trabajo. 
Siguiendo esta línea, la representación poética de China se da a través de un contacto real, transitorio, cercano y profundo; dicho de otro modo, se aleja un tanto de otras maneras que ha tenido la literatura occidental para representar China (o lo oriental) según un carácter sumamente superficial, interesado en lo ornamental y exótico. Además, el ejercicio propuesto por Barquero es más de carácter estético que político. La experiencia contenida en El viento de los reinos es un tanto mística, se aproxima a la búsqueda del origen de la humanidad. A partir de dicho aspecto, el poeta trae en su escritura una exploración de los sitios más remotos e ignotos, de una forma hermética que alude al movimiento y a la quietud del tiempo. En otras palabras, cuestiona su lugar en el mundo en relación con los elementos de la naturaleza para sublimarlos, no para repetirlos; adopta una construcción poética a partir de una China primordial, un lugar-otro, donde la materialidad misma le permite trasladarse desde el exterior hacia el interior, para luego volver allugar-fuera-de-sí en forma de poema.

Ahora bien, considerando que estamos ante un autor occidental que pone sus ojos en China, el presente trabajo nace de las contribuciones a los estudios literarios hechos por Edward Said en su obra Orientalismo, y todos los estudios recientes ligados a esta corriente crítica. En primera instancia, lo que fundamenta la propuesta de este autor es su experiencia misma: palestino nacido bajo el mandato británico, que se forma bajo una educación anglocéntrica, en la cual observó que "Aunque [le] enseñaron a creer y pensar como alumno inglés, también [le enseñaron] a comprenderque era extranjero, un Otro no europeo" (1998: 1). Así, comprendió la dimensión negativa en el acercamiento lingüístico-cultural-racial desde Occidente con ojos en Oriente; acercamiento que, en sí, mantiene un alejamiento. De acuerdo con Said, cierto es que lo autodenominado Occidente se ha auto-otorgado la facultad impositiva, a partir del ideal imperialista, de confeccionar el imaginario del Otro a partir de su literatura. Muy tempranamente, Said es consciente de que la escritura en el mundo opera "como construcción de realidades que sirven de instrumento a uno $u$ otro propósito" (1998: 1), desarrollando su visión crítica al respecto y postulando, en 1978, aquello que denominará "Orientalismo". En esta, la obra pilar de los estudios subalternos, Said establece la pretensión europeizante de abarcar el mundo desde su visión centralizadora y dominante sobre los márgenes del mundo. Sin embargo, no olvidemos la doble articulación de este proceso ideológico: al generar el imaginario de otro, se está elaborando la imagen de uno-mismo; así lo grafica el autor: "Oriente ha servido para que Europa se defina en contraposición a su imagen, su idea, su personalidad y su experiencia. Sin embargo, Oriente no es puramente imaginario" (2002: 20). En ese sentido, se confirma la construcción de un imaginario a partir de intertextualidades $y$ conjeturas que generalmente no reflejan verídicamente la esencia de la realidad referida de, en este caso, China. Así, se hace fundamental revisar las prácticas discursivas de los autores occidentales que se refieren a la cultura oriental, ya que esto supone una intención política, ya sea explícita o implícita, mediante la cual los intelectuales han forjado un ideario a partir de su lugar de enunciación autoritaria. En este sentido, Said postula: "el orientalismo se puede describir y analizar como una institución colectiva que se relacionaconOriente, relaciónqueconsisteen hacer declaraciones sobre él, adoptar posturas respecto a él, describirlo, enseñarlo, colonizarlo y decidir sobre él; en resumen, el orientalismo es un estilo occidental que pretende dominar, reestructurar y tener autoridad sobre Oriente." (2002: 21) Bajo esta perspectiva, los casos que revisa Said son de sinofobia, cuyas representaciones "reiteran la superioridad europea sobre un Oriente retrasado" (27). En ese sentido, existe en la actitud orientalista un intento de resaltar tajantemente la alteridad de manera inferior, meramente estetizada, descriptiva, o erotizada, fuera de la propia moral, inversa y primitiva; la otredad como sumamente mudo o incapaz de representarse a sí mismo, con la necesidad de ser explicado desde otro lugar, ajeno, el cual se dispone como jerárquicamente superior. En el caso de Barquero, veremos lo contrario; más bien, su construcción de una China imaginaria no remite, como hemos dicho, meramente a un ejercicio político, sino más bien ligado fundamentalmente a lo estético. Según este interés, corresponde más dialogar la propuesta de Barquero con los cuestionamientos de Victor Segalen respecto a la "experiencia exótica" resultante del contacto con la otredad.

Dicho lo anterior, el problema que será abordado es el de la aproximación a una tierra 
desconocida que permite los planteamientos sobre el misterio de la vida y las entrañas que nos forman, nos modelan y dan lugar en el mundo. Aquí se considera que aquello articularía una transportación mística a partir del poder de la palabra, yendo al límite de lo no-pensado, surgiendo al mismo tiempo el pensamiento y el ensueño. Esto funda una especie de planteamientos vitales sobre la estética de su obra: en el centro encontramos la humanidad, su existencia, en relación con aquello que lo rodea y lo conforma: lo otro; revelando, al mismo tiempo, la sustancia más primitiva del hombre en el mundo, la creación ligada al cambio esencial como comportamiento natural de cada elemento.

Expuesto lo anterior, la presente publicación constituye un análisis de las consideraciones del viaje en torno al imaginario del extranjero, y el complejo proceso vinculado a la "experiencia exótica", en la cual definiremos la realidad del "éxota" según Segalen y compartiremos dicho supuesto teórico con las nociones que en los poemas nacen simultáneas a la concepción del viaje, como el tiempo y el espacio laberíntico, que constituyen a su vez el exotismo y la anábasis, conceptos en los que el autor constata su tradición literaria ligada a Saint-John Perse. De este modo, el capítulo estaría destinado a responder qué es aquello que Barquero encuentra en dicha construcción imaginaria de una China milenaria y de qué modo se representa. En líneas generales, tendremos un panorama característico de este encuentro con el pasado, siempre con una visión crítica del presente, manteniendo en su búsqueda el misterio de la propia existencia, desde el origen hacia el porvenir.

\section{DESARROLLO}

Bajo el criterio de análisis ya expuesto, el poemario se articula en dos vertientes: 1) vínculo con el suelo visitado, el cual permite al viajero idealizar el lugar y 2) la concepción de auto-saberse extranjero ante el entorno autóctono, tratando de construir un vínculo más allá del contacto mismo.

En este sentido, cabe decir que el hablante poético de Barquero (aunque luego descubramos que existe una suerte de polifonía entre poemas) no posee la característica propia de un cronista, es decir, no aporta información detallada del lugar que visita, o de algún suceso que le parezca extraño, por tanto no existe un intento meramente descriptivo ni enciclopédico; más bien, la figura del extranjero no ambiciona otra cosa que permanecer vinculado al entorno, a partir de sus sentidos, sus extremidades (manos y pies) y su conciencia (ensueño e imaginación). Con esto se quiere decir que el asombro de enfrentarse ante lo extraño contiene, como trasfondo, algo más que un desplazamiento geográfico: el viaje emprendido por Barquero supone un umbral entre el interior del sujeto y el entorno; umbral que está sostenido en lo sugerente de la escritura poética. Dicho lo anterior, la propuesta de este capítulo es analizar la forma en que se encarna poéticamente el rol de "éxota»; y cómo, mediante el contacto, reimaginar una China milenaria permiteal extranjero reencontrarse consu propia identidad. A partir de ahí, con la intención de desentrañar la conexión entre Occidente y Oriente establecida por la escritura de Barquero iniciada en China, me basaré en fragmentos de poemas y/o imágenes poéticas, que refieran al viaje, al tiempo, y al orden extraño al cual se enfrenta; todo esto, será tratado principalmente a partir de la propuesta teórica de Victor Segalen en su Ensayo sobre el exotismo. De dicho modo, procederemos a responder algunas preguntas que surgen como relámpagos atravesando una pradera: ¿Ante qué tipo de mirada se desenvuelve el mundo recreado?, ¿qué elementos surgen simultáneos a la mención de extranjería? ¿El hablante explora dentro de su propia existencia, en busca de un "otro" y de sí mismo? Por último, ¿es posible asegurar una asimilación con sus antecedentes literarios, o de lo contrario diferenciarlo?

El viento de los reinos se inscribe en una tradición literaria que debe su producción al vínculo entre el autor y una cultura, hasta ahora, exótica. Digo 'hasta ahora', porque existe un punto donde

\footnotetext{
4. Cabe mencionar que todos son franceses. Constituyen un selecto grupo de destacados nombres en el área humanista: poetas, novelistas, sociólogos, diplomáticos, etc. Marcel Granet, por ejemplo, fue quien inició metodologías sociológicas al estudio de China, escribió, fundamentalmente, La pensé chinoise (1934). Aunque todos mantiene un vestigio de vínculo con China, en el presente trabajo acudiremos sólo a lo postulado por Segalen respecto a la experiencia exótica, y a Saint- John Perse, con el cual Barquero comparte una intención literaria.
} 
quien escribe reconoce el encuentro de diferencias, pero desconoce el resultado de su propia escritura. Ya desde la dedicatoria, es posible visualizar la dirección estética del autor, y deducir el sentido de su huella en un país extranjero: "A mis antecesores en la ruta interior a la China primordial: Paul Claudel, Victor Segalen, Saint-John Perse, André Malraux y Marcel Granet" (Barquero, 1967: 9)4. Entre este grupo de autores, en particular es Segalen quien nos entrega un criterio teórico para comprender el viaje emprendido y la China poetizada por Barquero, que mantiene, bajo el signo de lo lejano e incognoscible, silencioso, un tono poético constantemente cubierto por un aire de solemnidad, que no pretende menospreciar ni destruir.

Segalen, en su ensayo anteriormente mencionado, esboza, reflexiona y reescribe su intenso cuestionamiento sobre el asunto del enfrentamiento ante lo "otro" como una experiencia estética. En ese sentido, reelabora el significado de "exotismo", en contraposición a la reducción del término, es decir, dicha experiencia no alude ya al simple tópico del viajero turista o colonizador, los cuales vendrían siendo dos retratos desprovistos del verdadero significado de la experiencia exótica. De ahí parte Segalen su pensamiento, desde el conflicto contra aquellos que intercedieron un lugar ajeno y se vislumbraron, pero sus síntesis literarias quedaron inconclusas en tanto "Ellos dijeron lo que vieron, lo que sintieron en presencia de las cosas y de los seres inesperados cuya impresión iban a buscar. [Sin embargo,] ¿Revelaron lo que esas cosas y esos seres pensaban para sí y de sí mismos?" (1989: 15). He ahí el vacío en la experiencia del cual sospecha y desconfía; son "seudoéxotas (los Loti, los turistas (...) Yo los llamo proxenetas de la sensación de lo diverso)" (1989: 31). En contraste, según Segalen, aquel que se hace cargo de esa experiencia ante las diferencias no es conceptualizado como orientalista ${ }^{5}$, sino denominado "éxota": "aquel que, como viajero nato por los mundos de diversidades maravillosas, siente todo el sabor de lo diverso" (1989: 27). El concepto nace del prefijo "exo", que significa "Todo lo que está "fuera" del conjunto de nuestros hechos de conciencia actuales y cotidianos, todo lo que no es nuestra "tonalidad mental" acostumbrada" (1989: 17).

Ahora bien, si el éxota no es un sujeto hermético, en tanto genera un diálogo con su entorno, aceptando la diferencia intrínseca entre los seres de un paisaje o multitud, una respuesta inmediata dirá que su experiencia es constante, sin embargo, aquello que fundamenta el contacto-diálogo no es esencialmente la percepción misma ante la otredad, sino la distancia que precisa mantener, para luego hacer el ejercicio de enfrentarse a sí mismo. En ese sentido, las palabras de Segalen que debemos tener en mente, para considerar a Barquero, desde el comienzo, como un éxota sumamente segaleano, son las siguientes: "no podrá ser el yo [quien] siente... sino por el contrario, la interpelación del medio al viajero, de lo Exótico al Éxota, que lo penetra, lo asalta, lo despierta y lo perturba. Predominará el tú." (1989: 18) Así, dejando en claro el tipo de mirada posicionada ante China, es necesario precisar que Barquero, en todos sus hablantes poéticos, no abarca la realidad de forma enciclopédica u meramente, descriptiva, sino que poetiza, devela, sugiere, una construcción de la China milenaria; tampoco intenta explicar la realidad de la otredad por medio de una integración a lo común, es decir, no la adapta; por el contrario, se abraza firmemente en su búsqueda, regocijándose de la inminente diferencia y enfrentándose consigo mismo. De este modo, el autor logra la experiencia exótica, fiel a su estética; de la mano con lo postulado por Segalen, El viento de los reinos, o el viaje mismo, se inicia ante las "Puertas de China", poema cuyo hablante interpela al extranjero:

Extranjero, detente en mis murallas/ contengo tantos muertos que entera soy de cal y espinas/ (...) / no verás mi desnudez que el viento cuida/ conmigo dormirás sin conocerme/ en mis rodillas dormirás el sueño devastado del invierno/ (...) / En el hombre encontrarás refugio/ en el templo hallarás el aire que te niego/ junto a Buda la obscuridad de mi memoria/ de mí saldrás como has venido/ no verás sino mi anchura inabarcable/ no tendrás otra cosa que el silencio. (Barquero, 1967: 11-12)

\footnotetext{
5. Segalen jamás menciona un precedente de este término, acuñado aproximadamente setenta años más tarde. Aquí se utiliza para plantear en muy grandes rasgos su distinción, mentalizando al orientalista desde su negatividad, y al éxota dándole sentido desde la poética de Barquero.
} 
Como es posible apreciar a simple vista, el poema manifiesta el recurso literario de la prosopopeya; a saber, consiste en otorgar a entidades inanimadas, sin facultad de voz, características $\mathrm{y} / \mathrm{o}$ cualidades propias de seres animados. En este caso, es conferido el poder de la palabra a lo que el autor llama simbólicamente "China primordial", por lo tanto, no es una construcción desde lo ignoto, sino desde un lugar de enunciación imaginario en que la nueva experiencia es recuerdo de todas las anteriores, diferentes a la presente. Sin duda, el primer resultado de esta experiencia exótica es contundente, dado que el poeta se auto-representa como forastero en vista de una suerte de oráculo, puesto que el referente, en este caso las puertas, profetiza, de cierta forma, cómo será su vínculo con el éxota; a saber, declara su perfil de algo sumamente remoto temporalmente y milenario, al denominarse un enorme cementerio, cuyo ser está protegido por su propia invisibilidad. Así, al simbolizarse un pasado de China, se le postula como un ser de carácter ambiguo, como una puerta misma, cuyo sentido es de un lugar de transición, un umbral entre exterior e interior, mientras advierte que dentro de sí nada se halla ni se entrega. Cabe mencionar que en este poema se demuestra el primer indicio de que, además de haber emprendido un viaje real-concreto, el vínculo con lo exótico se da a partir de una visión, lo que se concluye en un viaje onírico; esto es mencionado por el propio autor en su libro autobiográfico Arte de vida, donde argumenta, anecdóticamente, el germen poético del poemario a través de un ensueño:

Se me ocurrió la idea de subir a la colina de Peihai, donde está la Pagoda Blanca, para observar desde lo alto la vieja ciudad prohibida. Y alli obtuve la visión más importante para mí, visión que alimenta buena parte de mi libro El viento de los reinos. Allí, obtuve, por un segundo, la imagen milenaria de la Gran China, no sólo de ese espacio infinito, de ese ocre de tierras viejas, que impregna todas las cosas, de ese cielo de losa craquelada, sino de un grande, lejano, sordo rumor; de un viento enorme que arañaba el polvo seco, de un viento donde se mezclaban todas las voces: voces de sangre, de dolor, de ira, de triunfo, voces de catástrofe (Barquero, 1970: 268).
Como ya hemos mencionado, es un hecho que Barquero viaja a una China moderna; pero nada de ella está comprometido en su obra. El poeta no aborda el presente como tal, sino en relación intrínseca con el pasado. Sin embargo, el problema surge ya que al referirse al pasado, se hace desde un futuro, por tanto, sólo importa descubrir lo que ha perdurado y recrear el mundo perdido por medio del lenguaje poético. En este sentido, siguiendo la lectura de Segalen, damos cuenta que estamos ante un exotismo en el tiempo, por el cual la experiencia se torna una búsqueda de lo oculto o borrado, y un vínculo emocional ante sus huellas: "todo se vuelve íntimo abandono/ ruinosa edad que en mí no vence a la ternura de lo puro y otorgado/ desolado invierno que en mí no puede escatimar la pérdida del mundo/ a través de mí se siguen hablando las eternas palabras." (1967: 102) El último verso es clave: Barquero es guardián de una verdad olvidada, abandonada, cuyo centro se desenvuelve en el rito de la memoria.

Lo anterior hace pensar la relación de Barquero con la poesía lárica escrita en Chile, (Jorge Teillier, Juvencio Valle, Rolando Cárdenas, Alfonso Calderón, entre otros), aunque con ciertos matices propios de cada poética; aquello que los agrupa, sin ponerse de acuerdo, es una resistencia ante el proyecto de modernización que abruma al ser-humano, y "atacados por la nostalgia, el mal poético por excelencia, vuelven a la infancia y a la provincia, (...) [rechazando] estas megapolis que desalojan el mundo natural y van aislando al hombre del seno de su verdadero mundo" (Teillier, 1965: 2). En ese sentido, es posible asegurar que la perspectiva hacia el pasado de China, por parte de Barquero, constituye una búsqueda de una Edad de Oro, "que no se debe confundir sólo con la de la infancia, sino con la del paraíso perdido que alguna vez estuvo sobre la tierra." (Teillier, 1965: 4) Sin embargo, este sentido en la poética de Barquero se da en el aquí y ahora, no en la memoria ni en la nostalgia, ya que realmente lo posiciona en diálogo con el presente.

En la entrevista que realiza Cristian Warnken al poeta en 1999, el autor declara que su viaje le ratificó la existencia de una relación intrínseca entre Occidente y Oriente; expone: "en el fondo descubrí una similitud en lo profundo, no en lo exterior, estereotipado ... sino que 
ciertos elementos ... volvemos a los vínculos, a la ceremonia ... China oculta y guardada ... descubrí en esa misteriosa relación todo nuestro inconsciente de la antigüedad". De esta manera, efectuando un desasimiento ante el presente considerado como superficial enemigo, la figura de éxota en Barquero se refugia en el lar para configurar un recuerdo colectivo, la antigüedad, que se da en una convivencia con los muertos ${ }^{6}$, propios del paso del tiempo: "todo era demasiado humano/ corporal como alguien que duerme/ había aprendido el polvo a ser polvo/ la piedra a ser piedra/ los hombres habían aprendido a reposar/ a ser carne de sus propios dioses" (1967: 70). Aquí, el hablante tiene ante sus ojos el pasado, donde se reconoce el estado natural de las cosas y la esencia humana a través de la muerte, lo cual, inmediatamente supone una confluencia de tiempos que permiten la reaparición de un mundo perdido como reflejo de lo universal; de esto nos habla en el poema "Maceración" donde los tiempos se confunden: "Las edades se suceden/ desaparecen tras las puertas dejando sólo un rumor de armaduras deshechas/ (...)/ vivo un reinado y otro/(...)/ dos mundos se unen, se confunden/ dos reinos enemigos habitan un mismo otoño silencioso/ dos épocas diferentes mezclan sus olas en el mar de la luna" (1967: 8788). De este modo, el gesto de Barquero es el de adentrarse imaginariamente en una remota China que aún subsiste en lo más oculto; oculto porque el viaje es infinito y su término cuestionable, ya que hace probable el no-lugar.

En este punto del viaje, vuelve a hacerse presente el símbolo de la puerta, como transición temporal hacia otro orden, el cual opera como síntesis del traslado entre diversos mundos. En el poema que sucede a "Puertas de China",

\footnotetext{
6. De hecho, el seudónimo Barquero podría remitir justamente al personaje de Caronte, encargado de trasladar las sombras errantes de los difuntos de un lado a otro del río Aqueronte en el Hades griego, el barquero. De este modo, el poeta plantea su poesía como un trasladar mundos entre mundos; noción ya trabajada en uno de sus poemarios próximos e incluso anteriores, como advertimos en El pan del hombre: "A veces el sueño nos separa, / porque hay orillas, tú lo sabes: / el amor es una de ellas, la orilla más atardecida. / La otra es el temor de vivir." (“Las orillas” 80).
}

titulado "La noche larga", demuestra la voz misma del éxota, como una suerte de respuesta al poema anterior, dialogando ya inmerso en la sensación de lo diverso y presentando esta misma amalgama de tiempos:

Todo ha sido como venir / callar/ detenerme a la
entrada de una puerta/ como ante una sola estatua
socavada/ respirar la obscuridad del tiempo. / (...)
ante una casa sin ventanas sólo puertas y puertas
encontré/ cada una se abría para mí/ cada una
aumentaba de espesor/ yo debía en silencio
atravesarlas impulsado por la sola obscuridad. /
Cada puerta era idéntica a la otra/ era yo el que
hallaba más grandes los espacios/ más altas las
columnas de la tierra. / Todo fue como avanzar/
avanzar/ oliendo la humedad de una estancia
nuevamente abandonada (1967: 13-14).

Así, la noción de adentrarse en lo desconocido se impone en esta doble articulación de movimiento y perplejidad, del hablante $\mathrm{y} / \mathrm{o}$ del espacio. Como es posible apreciar, el texto presenta el viaje como un ingreso a un laberinto de estatuas, interpretando al mundo como un caos que refleja desamparo y angustia, un mundo poético trasladado al imaginario chino: "Adónde conducían las puertas sino al más profundo silencio." (1967: 29) Cabe mencionar que Barquero no es el primer autor occidental en imaginar una China primordial a partir de una representación laberíntica. Kafka escribe su relato "Un mensaje imperial", cuyo argumento básicamente es la entrega secreta de un mensaje dictado por el emperador en su lecho de muerte a un mensajero. $\mathrm{Y}$ el asunto del mensaje es, metaliterariamente, el infinito impedimento que tiene el mensaje para llegar al destinatario, el lector; ya que el intermediario sufre un trayecto fatigosamente interminable: "Aún se está abriendo camino por las estancias del palacio más recónditas; nunca las dejará atrás; y aunque lo consiguiera, no se habría ganado nada; tendría que atravesar los patios; y después de los patios, el segundo palacio circundante; y otra vez escaleras y patios; y otra vez un palacio; y así a lo largo de milenios" (Kafka, 2012: 193). Al igual que en Barquero, no hay mención explícita de China, sino que recurre a mencionar espacios interminables, al mito propio de estar hablando otro lenguaje, a una vastedad dada en la representación 
imaginaria que invade al éxota, haciéndole saber la posibilidad de traducir el silencio del pasado en lenguaje poético. Si pensáramos el pasaje de Kafka dirigido a Barquero, cabría preguntarse si éste último logró llegar o recibir el mensaje; responderíamos que sí, y más: Barquero consiguió adentrarse en el laberinto del pasado y salió para redimir el exotismo; en el poema titulado "Laberinto" se lee: "Si algo encontré son puertas que comunicaba un aire frío/ altas puertas que cuidaban el laberinto del dragón/ el solemne sonido de mis pasos/tronos vacíos en un orden de silencio, edad y aldabones" (1967: 67); aquí queda demostrada la propiedad del proyecto de Barquero, cuya intención, como hemos visto, se basa en introducir un tiempo ahistórico, suspendido, poético, mediante el cual se revela la experiencia exótica como un reordenamiento del ser, caótico, sinestésico:

\begin{abstract}
El tiempo ardía apagando los rostros/ se inmovilizaban los años para escuchar el grave sonido/ se ordenaban en círculo los animales de piedra/ las puertas se abrían con lentitud crepuscular/ yo avanzaba guiado por el centro de mí mismo/ por el extraño peso de mi alma (...) mis ojos palpaban como manos/ mis oídos rechazaban lo exterior/ nada me era más ajeno que mis pies/ nada me era más distante que mis brazos (1967: 25).
\end{abstract}

En este fragmento se percibe el hechizo: el éxota se olvida, por momentos, de su cuerpo para vincularse con el espacio donde se moviliza y estar en contacto con el mundo concreto; esto es, el hablante no se encuentra fuera del mundo, fuera del todo, él nombra los objetos y los concibe restituidos, revelados, bajo otro orden, lo que le afecta en la medida que va perdiendo su individualidad, ya que la mirada establece lo percibido bajo un régimen de convivencia. Por lo demás, mediante el laberinto y las estatuas, propias de un pasado milenario, el éxota se descubre ante la otredad en el orden oculto de la muerte; en el poema "Tumbas Ming" el espacio vinculado al sujeto termina siendo la noción de casa, que le permite reconstruir una acción universal como lo es el alimentarse o dormir; esto lo logra, desenterrando, es decir, reviviendo el recuerdo de una primera casa que justifica la casa en la otredad:
La tierra devuelve las cosas con el orden de una vieja mesa/ como ubicada para siempre entre la mano y la turbada boca/ uno siente que hay lugares invariables/ que todo es recuerdo de los hombres/ (...) / me fue preparado este momento para estar más cerca de la ciudad desenterrada/ me fue dado penetrar en esta casa donde nada ha cambiado/ donde todo parece dormir o despertar (1967: 45).

En torno a lo anterior, nos acercamos al gran motivo del poemario, cuyo centro es la fraternidad entre diferencias, dada a partir del paso desde un "yo" enfrentado con la lejana "otredad", hacia el vínculo de dos mundos sintetizados en un "nosotros" que anula la diferencia que, por lo demás, la poesía se encarga de ceder cierto fenómeno de conflicto o concordancia. Respecto a este punto, nuevamente son pertinentes de las palabras del propio autor que relata biográficamente un pasaje de su estadía en China: "Tuve como el sombrío desespero, como la sensación de despertar, ya muy tarde, de un largo sueño; de haber estado ahí, en alguna edad; de alcanzar con fatiga a otro que me esperaba en Peihai; de batallar con él para entrar en un solo cuerpo, que era el mío y que, por un instante, no tenía nombre" (1970: 268-269). Esta cita argumentaría, como se ha deducido, la estadía del hablante poético en el orden de un tiempo pretérito, vivido a través del ensueño, lo cual le facilita hablar, y ampliar el espectro poético de su propia identidad mediante el encuentro con un lugar otro, común. A propósito, existe otra pista trazada por el propio autor, éste dice: "Quería hacer algo más universal que en mis primeros libros. Muestro a China vista por un extranjero. No me hago el chino. Quiero decir que la veo desde fuera. (...) [Y agrega:] Hay una similitud con Anábasis y Exilio, de Saint-John Perse, uno de los poetas a quienes dediqué El viento de los reinos". Pues revisemos si eso fue posible y de qué manera la experiencia exótica se complementa en el poemario con la noción de "anábasis" en SaintJohn Perse.

Premio Nobel de literatura en 1960, considerado uno de los poetas más influyentes en esas décadas, publica en 1924 su poemario titulado Anábasis, escrito durante su estadía en China como embajador, cuestión que revela una primera similitud con Barquero, sólo que éste último no relaciona su estancia en Oriente desde 
un cargo político. Saint-John Perse, nacido cerca de la isla Guadalupe en las Antillas francófonas, vivió constantemente trasladándose de un país a otro, causa por la cual su producción literaria ha sido descrita en base al sentimiento de expatriado y a una intención cosmopolita. El filósofo Alain Badiou, respecto a Saint-John Perse y Paul Celan, por haber utilizado la noción de "anábasis" en sus propuestas poéticas, conceptualiza el Siglo XX mediante esta noción, entre otras:

\footnotetext{
Vemos asomar lo que hace de la palabra "anábasis" el posible soporte de una meditación sobre nuestro siglo. En efecto, el término, en la trayectoria que nombra, deja sin decisión las partes respectivas de la invención disciplinada y de la errancia azarosa, y hace una síntesis disyuntiva de la voluntad y el extravío. Por lo demás, la palabra griega ya atestigua esa indecidibilidad, porque el verbo $\alpha v \alpha \beta \alpha v \varepsilon$ Iv ("anabasear”, en suma) quiere decir a la vez "embarcarse" y "volver". Este apareamiento semántico conviene, sin ninguna duda, a un siglo que no deja de preguntarse si es un final o un comienzo (Badiou, 2005: 111).
}

Así, mientras el producto de la "anábasis" es la ida y la vuelta, donde dicho retorno no es la vía por la cual se llegó sino la invención de un camino de regreso, el hablante encontrará su orientación en la imperativa fraternidad "mediante la cual el "yo" puede ser recíproco del "nosotros", es una condición de la aventura, su sustancia subjetiva." (Badiou, 2005: 121) De este modo, la fuerza nihilista en forma de epopeya de Saint-John Perse, contiene un canto a la humanidad misma, a todos los habitantes del mundo, a todos los oficios y a las cosas, pero también a la soledad del individuo, resultado de la constante extranjería en movimiento:

\footnotetext{
"iSoledad! A nadie he dicho que espere... Me iré por ahí cuando lo quiera..." Y el Extranjero todo vestido con sus nuevos pensamientos, gana todavía partidarios en las vías del silencio: su ojo está lleno de una saliva, ya no hay en él sustancia de hombre. Y la tierra en sus simientes aladas, como un poeta en sus palabras, viaja...." (Perse, s/f: 62)
}

Siguiendo con el tópico: en Barquero, dicha fraternidad, o sentimiento de hermandad, designa la equivalencia del sujeto con lo "otro" tanto en una singularidad como en una pluralidad. En su caso, se reconoce al "otro" como parte del "yo", creando un ser unitario. Barquero nos declama: "uno es el extraño porque no quiso amar/ porque no quiso alterar su semejanza" (1967: 46). Por consiguiente, se construye una realidad alterada donde el éxota no habla sólo por él sino también por el entorno imaginado que lo asalta, que es la construcción espacial del pasado, el cual le permite visualizar su reflejo: "Son los años que vivieron con tu sangre" (1967: 28).

En síntesis, en los poemas "El único habitante" y "La ciudad desierta" confluyen todos los puntos que hemos revisado. La anábasis que realiza Barquero en su poemario se da mediante el constante vaivén entre lugares y tiempos. En el primero de ellos, el hablante se reconoce como éxota y sugiere su manera de contactarse con el mundo ajeno para reencontrarse a sí mismo, siendo parte de aquella realidad compartida. Piensa la muerte como el territorio del pasado, donde es posible dar con el primer muerto:

vine a reconocer con mi cuerpo/vine a empaparme en la humedad de los que no ansían despertar/ en ese cuerpo único que forman los seres en la raíz del invierno/ (...) / un solo ser podemos rescatar, el primer muerto/ el que a todos nos precede está más próximo" (1967: 52).

En el segundo, deja entredicho la conjunción con el otro a partir del tiempo único, que es el origen común de todos los seres. De esta forma, ir hacia el pasado luchando contra lo laberíntico, y reconocer en una total cercanía el mundo perdido, dormido, que guarda el orden verdadero de las cosas, le permite volver hacia el presente, pero aun estando dentro de una realidad atemporal:

\footnotetext{
Yo penetro en la muerte pero en verdad me reconozco/ voy a través de un río que nunca agota su substancia/ hay una fuente común a todo nacimiento, las raíces no se desarrollan/ son como los seres que no se pertenecen a sí mismos/ sino a un sueño más profundo donde todo es semejante/ hay una sola edad, ella es la espectadora de nuestros actos/ la ciudad desierta no me escucha, forma parte de mi largo destierro (1967: 58).
}

Por otro lado, al parecer ya regresado al punto de inicio, el hablante éxota evoca su situación en la 
anábasis misma, construyendo la imagen de sus antecesores relacionados con el exotismo originario en el tiempo poético, la experiencia maravillosa: "Vinieron de tantas regiones en caravanas lentas como los años/ aspiraron este olor ensombrecido, solo/ descubrieron que un magnífico animal mezcla de león, de unicornio/ devoraba a los hombres sin exterminar su descendencia" (1967: 47). Sin preámbulo, el hablante éxota no olvida que pertenece a un grupo heterogéneo de discursos agrupados por la experiencia ante lo otro. Además, es curioso que para hablar de esta tierra en la que se encuentra, acuda a la hegemonía del pasado, lo que hace pensar que cada nación está custodiada en el inconsciente para ser representada a partir de su origen. En ese sentido, ser consciente del suelo extraño es también tener nociones de sí mismo, por tanto, queda demostrado el diálogo en todo momento entre la subjetividad y lo percibido. El hablante se apropia de la experiencia de sus antecesores preguntándose precisamente por aquello que ellos vieron y respondiendo de forma reveladora para postular el sentido universal y cosmopolita censurado por las fronteras:

Qué vieron en este largo crepúsculo del mundo/ en este mar lavado de temor/ vieron al ser antes o después de su ruptura / (...) / Qué vieron en la antiquísima piedra de los rostros humanos / la vieja tregua entre la noche y la aurora/ la vieja semejanza y el frío despertar" (1967: 48),

Como es posible apreciar, para solucionar el problema del exotismo y la extranjería, el hablante del poemario de Barquero entrega sus soluciones sobre una constante, el orden y el tiempo; bajo dicho criterio, su visión de mundo confía en ordenar el caos de diversidades y se arriesga a la sentencia, apelando a la naturaleza compartida y a la misma metáfora del árbol, o rizoma, donde la semilla es el origen y las ramas son parte del laberinto conectado a un único tronco: "De todos es madre la campana, la piedra/ de todos es hija la ceniza/ habitamos a la vez una misma región inviolable (...) / en nuestra esencia de pueblos, de espigas, de árboles/ hay una sola raíz prisionera y olvidada" (1967: 40).

Sin embargo, aún no se completa la acción de anabasear: el éxota piensa también sobre el porvenir, específicamente en la quinta parte del poemario. Alli el imaginario se concentra, en gran parte, fuera de China, Vietnam; la voz poética del poemario, sin dejar de lado un trabajo en torno a la figura del "otro", ahora en contraparte con la hermandad que supone el "nosotros", vuelve a un presente concreto, histórico, desde el cual, además, están los ojos puestos en un futuro apocalíptico, desde la alusión al guerrero medieval que participó de la destrucción, pero conllevó a la paz de aquella china construida y albergada en el imaginario. De esta manera, el autor coordina una estrategia para hacer discutir la paz universal representada por la China primordial (pasado) versus la guerra de Vietnam (presente), en donde se encontrarían los verdaderos bárbaros, el extranjero invasor, que no anhela procrear en el ensueño de estar en otro sitio, sino aniquilar dicha instancia de paz y encuentro. En otras palabras, el viaje a China en post del absoluto, abstracto, algunas veces romántico, es desbaratado por otra realidad aún más inmediata e impuesta históricamente. En esta huida del imaginario chino, el autor proporciona una coexistencia conflictiva entre el orden sagrado y el sentido apocalíptico; se elabora otra visión de extranjero, el militar, ante el cual expone de manera categórica una denuncia ante su labor inhumana:

Tú que exterminas en Vietnam como un falso enviado / tú que exterminas en Vietnam en masa, en marejada, en bulto / tú que matas sin afrentar primero/ sin cubrir primero con tu manto el lugar escogido/ tú que matas también a la madre y a su hijo sin distinguir el rostro humano (1967: 126).

En otras palabras, se construye una imagen de extranjero sumamente contraria a lo que hemos estado definiendo como éxota; en este caso, se aprecia un símil a la barbarie, al enemigo más allá de las fronteras que no vendrá para vincularse al mundo, ya que su misión es aniquilar la diferencia, al otro-concreto, superarlo por medio de la muerte. Cabe mencionar, además, que, en este apartado del poemario, se presentan por primera vez algunas referencias a la modernidad, específicamente a las máquinas, al fusil, al helicóptero, todas vistas en relación con un imaginario terrorífico, desalentador, donde la humanidad ya no es reconocida, sino en la medida que se reduce a la muerte por medio de la guerra:

No habrá más tierra/ no habrá nadie que se acuerde/ los árboles crecerán/ se empezará a 
morir el sol, el corazón del tiempo/ se empezará a morir la raza, todas las razas/ la podredumbre se extenderá como una lava apagada/ los hombres olvidaron su rostro (1967: 114).

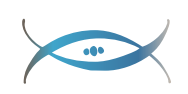

\section{CONCLUSIÓN}

A modo de conclusión, lo que produce Barquero es la concepción de la figura de un éxota que va a empaparse del entorno en un ir y venir temporal y laberíntico, consagrandoelimaginario de una China misteriosa e impenetrable, además de constatar el entorno como un ente que lo afecta en tanto lo interpela y le hace partícipe en un orden secreto que sólo puede ser abarcado mediante el lenguaje que articula la dimensión simbólica del pasado. De esta manera, el viaje es concepción de tiempo y estructuración del mundo. De ahí que la mirada hacia el presente con pulsión apocalíptica deduce el sentido de todo el poemario: vincularse con el origen mismo del mundo a partir de un viaje hacia la antigüedad, realizando una crítica profunda al tiempo presente, desolador. Se ha propuesto que la realidad que opera en el éxota-poético, hablante de El viento de los reinos, es el de la contemplación del exterior, no con la pretensión de formar parte de él, sino de producir síntesis; la más íntima expresión de su alma y su mente se condiciona a entrar en un estado exomismado. El entorno es la otredad transformada por la subjetividad en palabra reveladora, donde dicha otredad es la principal sustancia del fenómeno poético, porque es allí donde se encuentra el hablante. El exterior no se idealiza como un punto de no-retorno, sino desde el cual el "yo" puede leerse, comprenderse, y dialogar, entregando su más digna expresión al mundo, jugando con las palabras, creando símbolos y denunciando implícitamente el problema epítome de la modernidad.

\section{BIBLIOGRAFÍA}

ANÓNIMO (1976). I Ching. El libro de los cambios, Trad. de Helena Jacoby De Hoffmann [de la versión alemana de Richard Wilhelm]. Santiago de Chile: Cuatro Vientos Editorial.

BARQUERO, E. (2000). Antología. Selección y Prólogo de Naín Nómez. Santiago de Chile: LOM Ediciones.

BARQUERO, E. (1970). "Arte de vida" en: Aisthesis. Revista chilena de investigaciones estéticas. $N^{\circ} 5$ : "La Poesía y sus problemas en Chile". Santiago: Centro de investigaciones estéticas, Facultad de Filosofía y Ciencias de la educación, Pontificia Universidad Católica de Chile, 261-269.

BARQUERO, E. (1967). El viento de los reinos. Santiago de Chile: Editorial Nascimento.

BARQUERO, E. (1962). "Las puertas de China" en Revista Orfeo $N^{\circ}$ 21-22. Santiago de Chile, 10-12.

BADIOU, A. (2005). “Anábasis” en EI Siglo. Buenos Aires: Manantial, 109-128.

CHEN, G. (2015). La poesía china en el mundo hispánico. Madrid: Miraguano Ediciones.

CHENG, F. (2008). La escritura poética china. Valencia: Pre-textos.

LIBRO DE LOS CANTOS. (2013). Edición y Trad. de Gabriel García-Noblejas. Madrid: Alianza Editorial.

KAFKA, F. (2012). “Un mensaje imperial” en Ante la ley. Escritos publicados en vida. Barcelona: Debolsillo. 193-194.

PERSE, S. J. (s/f). Anábasis y otros poemas. Madrid: Ediciones Orbis. Edición exclusiva para Argentina, Chile, Paraguay y Uruguay: Hyspamerica Ediciones Argentina.

PÉREZ, F. (1969). "El viento de los reinos. Efraín Barquero." Reseña en La tribuna. Los Ángeles. N. ${ }^{\circ} 25$, Año I.

SAID, E. (2002). "Introducción" en Orientalismo. Barcelona: Random House.

SAID, E. (1998). "Entre dos mundos". Disponible en: https://www.mxfractal.org/F9said.html

SEGALEN, V. (1989). Ensayo sobre el exotismo. México D.F: Fondo de Cultura Económica.

TEILLIER, J. (1965). Los poetas de los lares: Nueva visión de la Realidad en la Poesía Chilena.

TODOROV, T. (2007). "Segalen" en Nosotros y los otros. Siglo XXI Editores.

EFRAÍN BARQUERO en La belleza de pensar (1999). Videograbación. Entrevista con Cristián Warnken. Versión disponible en Youtube: https://www. youtube.com/watch?v=AnSGuCL8T3A 